\title{
Novel Semi-IPN Nanocomposites with Functions of both Nutrient Slow-Release and Water Retention. 2. Effects on Soil Fertility and Tomato Quality
}

Haidong Zhao ${ }^{\dagger \ddagger}$, Jiang Song ${ }^{\dagger \dagger}$, Guizhe Zhao ${ }^{\dagger \ddagger}$, Yang Xiang ${ }^{* \dagger+}$, Yaqing Liu ${ }^{* \dagger \ddagger}$

† Shanxi Province Key Laboratory of Functional Nanocomposites, School of Materials Science and Engineering, North University of China, Taiyuan 030051,

\section{China}

‡ Research Center for Engineering Technology of Polymeric Composites of Shanxi Province, North University of China, Taiyuan 030051, China

Corresponding Author: Yaqing Liu; Yang Xiang

Tel. \& Fax: +86-351-3559669. E-mail address: 1yq@ nuc.edu.cn (Y.Q. Liu), zbdxxiangyang@163.com (Yang Xiang). 


\section{CONTENTS}

The preparation processes of all materials.

Scheme S1. Neutralization mechanism of potassium dihydrogen phosphate and alkali metal carbonate in soil.

Table S1. Specific data of nutrient release amounts during PSRF degradation.

Table S2. Specific data of nutrient release amounts during PSRF+SAP ${ }_{\mathrm{WS}}$ degradation.

Table S3. Specific data of nutrient release amounts during PSRF+SAPHEC degradation

Table S4. Specific data of nutrient release amounts during SI-PSRF/SAP WS degradation.

Table S5. Specific data of nutrient release amounts during SI-PSRF/SAPHEC degradation.

Table S6. Total weight and number of tomato fruits picked at different times.

Figure S1. Photograph of soil column leaching experimental device.

Figure S2. Weight loss rate (A) of PSRF, PSRF+SAP and SI-PSRF/SAP and pH (B), electric conductivity (C) of soils treated in the soil column leaching experimental.

Figure S3. SEM images of PSRF.

Figure S4. Photographs of representative tomato plants on day 100 of different material treatments.

Figure S5. Effects of PSRF, PSRF+SAP and SI-PSRF/SAP on $\mathrm{CO}_{2}$ flux (A) and $\mathrm{CH}_{4}$ flux (B) at different tomato growth periods. 
The preparation processes of all materials.

\section{Preparation of polymeric slow-release fertilizers (PSRF):}

Formaldehyde (4.06 g), urea (6 g) and deionized water (2.5 g) were added into a flask with constant stirring. After urea was dissolved, $\mathrm{pH}$ value of the solution was adjusted to 8.0 by adding a $5 \%(\mathrm{w} / \mathrm{w}) \mathrm{KOH}$ solution and maintained in a $40{ }^{\circ} \mathrm{C}$ water bath for $2 \mathrm{~h}$.

$0.5 \mathrm{~g}$ of $\mathrm{KH}_{2} \mathrm{PO}_{4}$ was added into a flask containing above methylolurea solution, then the temperature was raised to $55^{\circ} \mathrm{C}$ until a white viscous product was obtained, which was the polymeric slow-release fertilizers (PSRF) containing NPK.

\section{Preparation of super absorbent polymer containing wheat straw (SAPws):}

The wheat straw (WS) was first immersed in distilled water, soaked at $60^{\circ} \mathrm{C}$ in a drying oven for 12 hours, and then filtered. The filters were placed in a solution of $24 \%$ $\mathrm{KOH}$ and $1 \% \mathrm{NaBH}_{4}$, stirred at room temperature for 3 hours, and then filtered, washed repeatedly with distilled water until the filtrate was neutral, dried for later use.

$5.0 \mathrm{~g}$ of acrylic acid (AA), $2.0 \mathrm{~g}$ of acrylamide (AM) and $0.7 \mathrm{~g}$ of pretreated WS powder were added into a round bottom flask, the neutralization degree of AA was adjusted to $80 \%$ by adding a $20 \% \mathrm{KOH}$ solution. Then, $0.021 \mathrm{~g}$ of APS was added into the flask, the mixture solution was stirred in an ice water bath for 30 minutes. Then, the flask was placed in a water bath maintained at $55^{\circ} \mathrm{C}$, and the mixture solution was reacted for 4 hours at a nitrogen atmosphere to obtain a viscous product. Preparation of super absorbent polymer containing hydroxyethyl cellulose (SAPhec): 
$5.0 \mathrm{~g}$ of acrylic acid (AA), $2.0 \mathrm{~g}$ of acrylamide (AM) and $0.7 \mathrm{~g}$ of hydroxyethyl cellulose (HEC) were added into a round bottom flask, the neutralization degree of AA was adjusted to $80 \%$ by adding a $20 \% \mathrm{KOH}$ solution. Then, $0.021 \mathrm{~g}$ of APS was added into the flask, the mixture solution was stirred in an ice water bath for 30 minutes. Then, the flask was placed in a water bath maintained at $55{ }^{\circ} \mathrm{C}$, and the mixture solution was reacted for 4 hours at a nitrogen atmosphere to obtain a viscous product.

\section{Preparation of Semi-IPN Functional Nanocomposites(SI-PSRF/SAPws):}

$5.0 \mathrm{~g}$ of AA, $2.0 \mathrm{~g}$ of $\mathrm{AM}$, and $0.7 \mathrm{~g}$ of pretreated WS powder were added into a round bottom flask, the neutralization degree of AA was adjusted to $80 \%$ by adding a $20 \% \mathrm{KOH}$ solution. Then, $0.5 \mathrm{~g}$ of $\mathrm{KH}_{2} \mathrm{PO}_{4}, 0.021 \mathrm{~g}$ of APS and $6.0 \mathrm{~g}$ of methylolurea solution were added into the flask, the mixture solution was stirred in an ice water bath for 30 minutes. Then, the flask was placed in a water bath maintained at $55{ }^{\circ} \mathrm{C}$, and reacted for 4 hours at a nitrogen atmosphere to obtain a viscous product, which had the semi-interpenetrating polymer network of PSRF and SAP (WS-g-P(AA-co-AM) and was expressed as SI-PSRF/SAPws.

\section{Preparation of Semi-IPN Functional Nanocomposites (SI-PSRF/SAPHEc):}

$5.0 \mathrm{~g}$ of $\mathrm{AA}, 2.0 \mathrm{~g}$ of $\mathrm{AM}$, and $0.7 \mathrm{~g}$ of HEC were added into a round bottom flask, the neutralization degree of AA was adjusted to $80 \%$ by adding a $20 \% \mathrm{KOH}$ solution. Then, $0.5 \mathrm{~g}$ of $\mathrm{KH}_{2} \mathrm{PO}_{4}, 0.021 \mathrm{~g}$ of APS and $6.0 \mathrm{~g}$ of methylolurea solution were added into the flask, the mixture solution was stirred in an ice water bath for 30 minutes. Then, the flask was placed in a water bath maintained at $55{ }^{\circ} \mathrm{C}$, and reacted 
for 4 hours at a nitrogen atmosphere to obtain a viscous product, which had the semi-interpenetrating polymer network of PSRF and SAP (HEC-g-P(AA-co-AM) and was expressed as SI-PSRF/SAPHEC.

$$
\begin{array}{lc}
\mathrm{KH}_{2} \mathrm{PO}_{4} \rightarrow \mathrm{K}^{+}+\mathrm{H}_{2} \mathrm{PO}_{4}^{-} & \text {dissolution } \\
\mathrm{H}_{2} \mathrm{PO}_{4}^{-} \rightarrow 2 \mathrm{H}^{+}+\mathrm{PO}_{4}^{3-} & \text { ionization } \\
3 \mathrm{H}_{2} \mathrm{PO}_{4}^{-}+5 \mathrm{M}^{2+}+\mathrm{Cl}^{-} \rightarrow \mathrm{M}_{5}\left(\mathrm{PO}_{4}\right)_{3} \mathrm{Cl} & \text { precipitation } \\
3 \mathrm{M}^{2+}+2 \mathrm{PO}_{4}^{3-} \rightarrow \mathrm{M}_{3}\left(\mathrm{PO}_{4}\right)_{2} & \text { precipitation } \\
10 \mathrm{M}^{2+}+6 \mathrm{H}_{2} \mathrm{PO}_{4}^{-}+2 \mathrm{H}_{2} \mathrm{O} \rightarrow \mathrm{M}_{10}\left(\mathrm{PO}_{4}\right)_{6}(\mathrm{OH})_{2}(\mathrm{~S}) & \text { precipitation }
\end{array}
$$

\begin{tabular}{|c|c|c|c|c|c|c|c|c|c|}
\hline & Weight & $\mathrm{N}$ & N Release & $\mathrm{C}$ & C Release & $\mathrm{P}$ & P Release & $\mathrm{K}$ & K Release \\
\hline Items & loss & Release & Amount / & Release & Amount / & Release & Amount / & Release & Amount / \\
\hline & (g) & Amount & Weight loss & Amount & Weight loss & Amount & Weight loss & Amount & Weight loss \\
\hline Periods & & (g) & $(\%)$ & $(\mathrm{g})$ & $(\%)$ & $(\mathrm{mg})$ & $(\%)$ & (g) & $(\%)$ \\
\hline day 0 to day 10 & 8.06 & 3.22 & 39.95 & 1.61 & 19.98 & 98.30 & 1.22 & 2.50 & 31.02 \\
\hline day 10 to day 40 & 0.54 & 1.26 & 22.22 & 0.31 & 57.41 & 14.72 & 2.73 & 0.02 & 3.70 \\
\hline day 40 to day70 & 1.28 & 0.52 & 40.63 & 0.67 & 52.34 & 0.27 & 0.02 & 0.01 & 0.78 \\
\hline day 70 to day 100 & 0.28 & 0.17 & 64.29 & 0.06 & 21.43 & 0.14 & 0.05 & 0.01 & 3.57 \\
\hline
\end{tabular}

Scheme S1. Neutralization mechanism of potassium dihydrogen phosphate and alkali metal carbonate in soil.

\section{Specific data of nutrient release amounts of all materials}

Table S1. Specific data of nutrient release amounts during PSRF degradation. 
Table S2. Specific data of nutrient release amounts during PSRF+SAPwS degradation.

\begin{tabular}{|c|c|c|c|c|c|c|c|c|c|}
\hline Items & Weight & $\mathrm{N}$ & N Release & $\mathrm{C}$ & C Release & $\mathrm{P}$ & P Release & K & K Release \\
\hline & loss & Release & Amount / & Release & Amount / & Release & Amount / & Release & Amount / \\
\hline & (g) & Amount & Weight loss & Amount & Weight loss & Amount & Weight loss & Amount & Weight loss \\
\hline Periods & & (g) & $(\%)$ & (g) & $(\%)$ & $(\mathrm{mg})$ & $(\%)$ & (g) & $(\%)$ \\
\hline day 0 to day 10 & 11.3 & 3.32 & 29.38 & 2.81 & 24.87 & 90.04 & 0.80 & 2.42 & 21.42 \\
\hline day 10 to day 40 & 1.43 & 1.21 & 83.92 & 0.12 & 8.39 & 5.58 & 0.39 & 0.05 & 3.50 \\
\hline day 40 to day 70 & 4.12 & 0.19 & 4.61 & 0.11 & 2.67 & 8.80 & 0.21 & 0.01 & 0.24 \\
\hline day 70 to day 100 & 0.87 & 0.45 & 51.72 & 0.24 & 27.59 & 8.40 & 0.97 & 0.01 & 1.15 \\
\hline
\end{tabular}

Table S3. Specific data of nutrient release amounts during PSRF+SAP ${ }_{\mathrm{HEC}}$ degradation

\begin{tabular}{|c|c|c|c|c|c|c|c|c|c|}
\hline Items & Weight & $\mathrm{N}$ & N Release & $\mathrm{C}$ & C Release & $\mathrm{P}$ & P Release & K & K Release \\
\hline & loss & Release & Amount / & Release & Amount / & Release & Amount / & Release & Amount / \\
\hline & (g) & Amount & Weight loss & Amount & Weight loss & Amount & Weight loss & Amount & Weight loss \\
\hline Periods & & (g) & $(\%)$ & (g) & $(\%)$ & $(\mathrm{mg})$ & $(\%)$ & (g) & $(\%)$ \\
\hline day 0 to day 10 & 11.91 & 3.73 & 31.32 & 2.91 & 24.43 & 93.38 & 0.78 & 2.42 & 20.32 \\
\hline day 10 to day 40 & 2.28 & 0.97 & 42.54 & 0.31 & 13.60 & 5.45 & 0.24 & 0.04 & 1.75 \\
\hline day 40 to day70 & 3.43 & 0.25 & 7.29 & 0.20 & 5.83 & 9.53 & 0.28 & 0.01 & 0.29 \\
\hline day 70 to day 100 & 0.63 & 0.31 & 49.21 & 0.14 & 22.22 & 4.97 & 0.79 & 0.01 & 1.59 \\
\hline
\end{tabular}


Table S4. Specific data of nutrient release amounts during SI-PSRF/SAPws degradation.

\begin{tabular}{|c|c|c|c|c|c|c|c|c|c|}
\hline Items & Weight & $\mathrm{N}$ & N Release & $\mathrm{C}$ & C Release & $\mathrm{P}$ & P Release & K & K Release \\
\hline & loss & Release & Amount / & Release & Amount / & Release & Amount / & Release & Amount / \\
\hline & $(\mathrm{g})$ & Amount & Weight loss & Amount & Weight loss & Amount & Weight loss & Amount & Weight loss \\
\hline Periods & & (g) & $(\%)$ & $(\mathrm{g})$ & $(\%)$ & $(\mathrm{mg})$ & $(\%)$ & (g) & $(\%)$ \\
\hline day 0 to day 10 & 11.87 & 1.38 & 11.63 & 3.23 & 27.21 & 83.28 & 0.70 & 2.36 & 19.88 \\
\hline day 10 to day 40 & 4.16 & 1.02 & 24.52 & 1.46 & 35.10 & 5.45 & 0.13 & 0.07 & 1.68 \\
\hline day 40 to day70 & 2.51 & 2.24 & 89.24 & 0.18 & 7.17 & 9.53 & 0.38 & 0.03 & 1.20 \\
\hline day 70 to day 100 & 1.06 & 0.10 & 9.43 & 0.33 & 31.13 & 4.97 & 0.47 & 0.01 & 0.94 \\
\hline
\end{tabular}

Table S5. Specific data of nutrient release amounts during SI-PSRF/SAPHEC degradation.

\begin{tabular}{|c|c|c|c|c|c|c|c|c|c|}
\hline Items & Weight & $\mathrm{N}$ & N Release & $\mathrm{C}$ & C Release & $\mathrm{P}$ & P Release & K & K Release \\
\hline & loss & Release & Amount / & Release & Amount / & Release & Amount / & Release & Amount / \\
\hline & (g) & Amount & Weight loss & Amount & Weight loss & Amount & Weight loss & Amount & Weight loss \\
\hline Periods & & (g) & $(\%)$ & $(\mathrm{g})$ & $(\%)$ & $(\mathrm{mg})$ & $(\%)$ & (g) & $(\%)$ \\
\hline day 0 to day 10 & 11.79 & 1.85 & 15.69 & 3.31 & 28.07 & 86.17 & 0.73 & 2.36 & 20.02 \\
\hline day 10 to day 40 & 4.36 & 0.87 & 19.95 & 1.47 & 33.72 & 5.36 & 0.12 & 0.08 & 1.83 \\
\hline day 40 to day70 & 2.50 & 2.04 & 81.60 & 0.35 & 14.00 & 19.41 & 0.78 & 0.03 & 1.20 \\
\hline day 70 to day 100 & 2.13 & 0.12 & 5.63 & 0.67 & 31.46 & 2.53 & 0.12 & 0.01 & 0.47 \\
\hline
\end{tabular}


Table S6 Total weight and number of tomato fruits picked at different times.

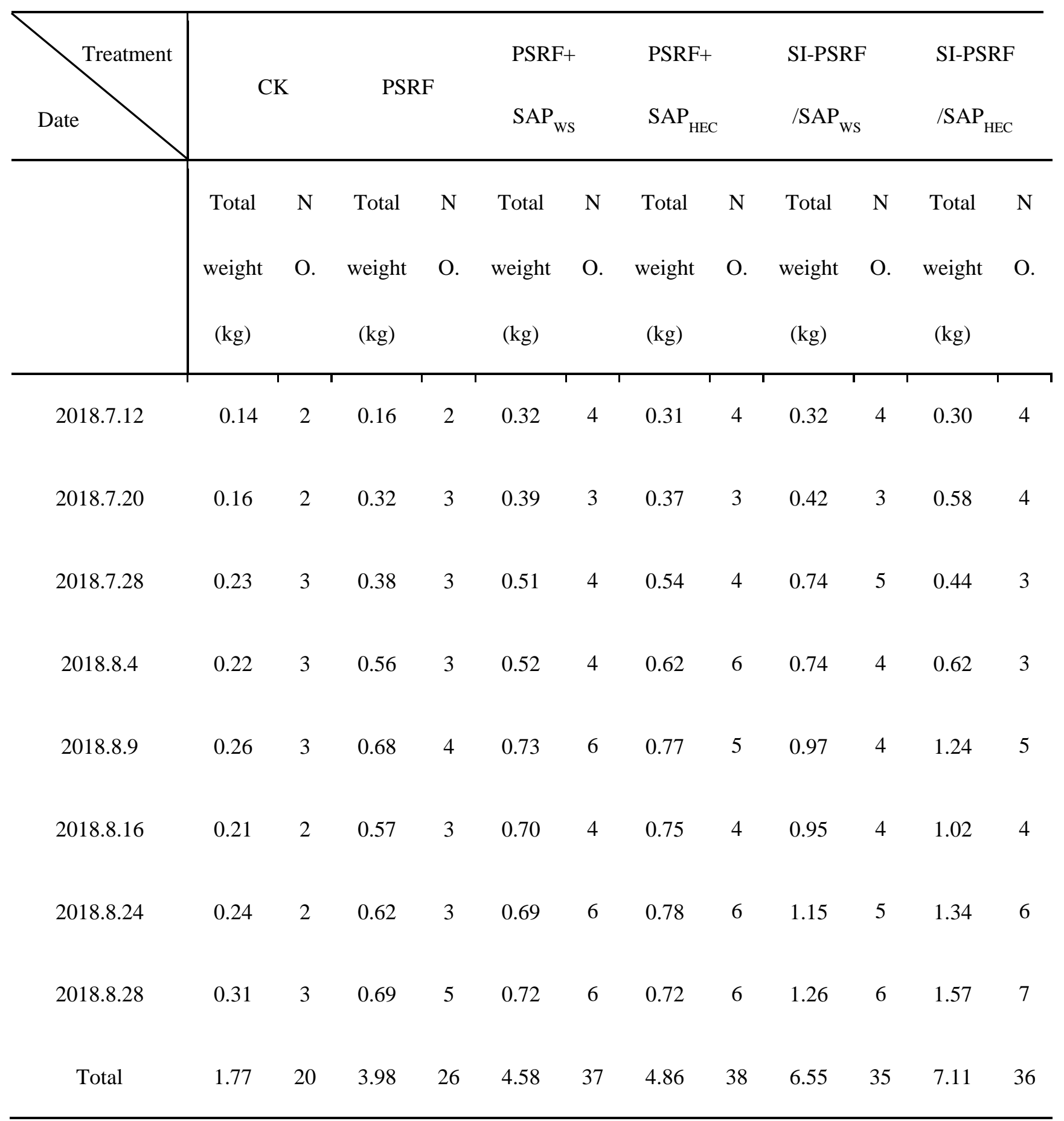




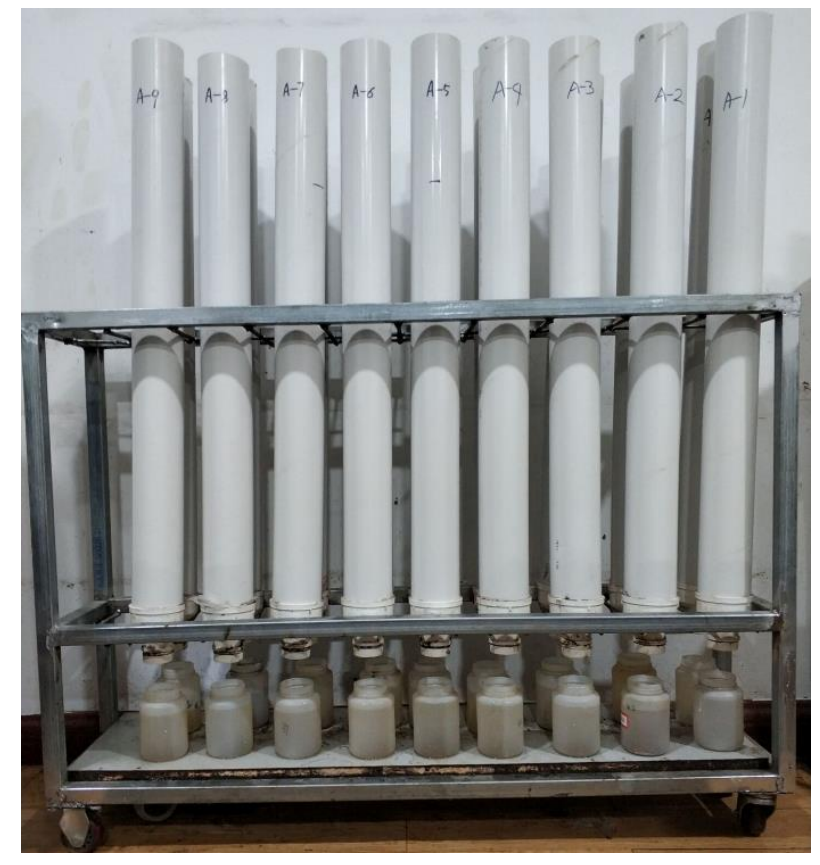

Figure S1. Photograph of soil column leaching experimental device. 

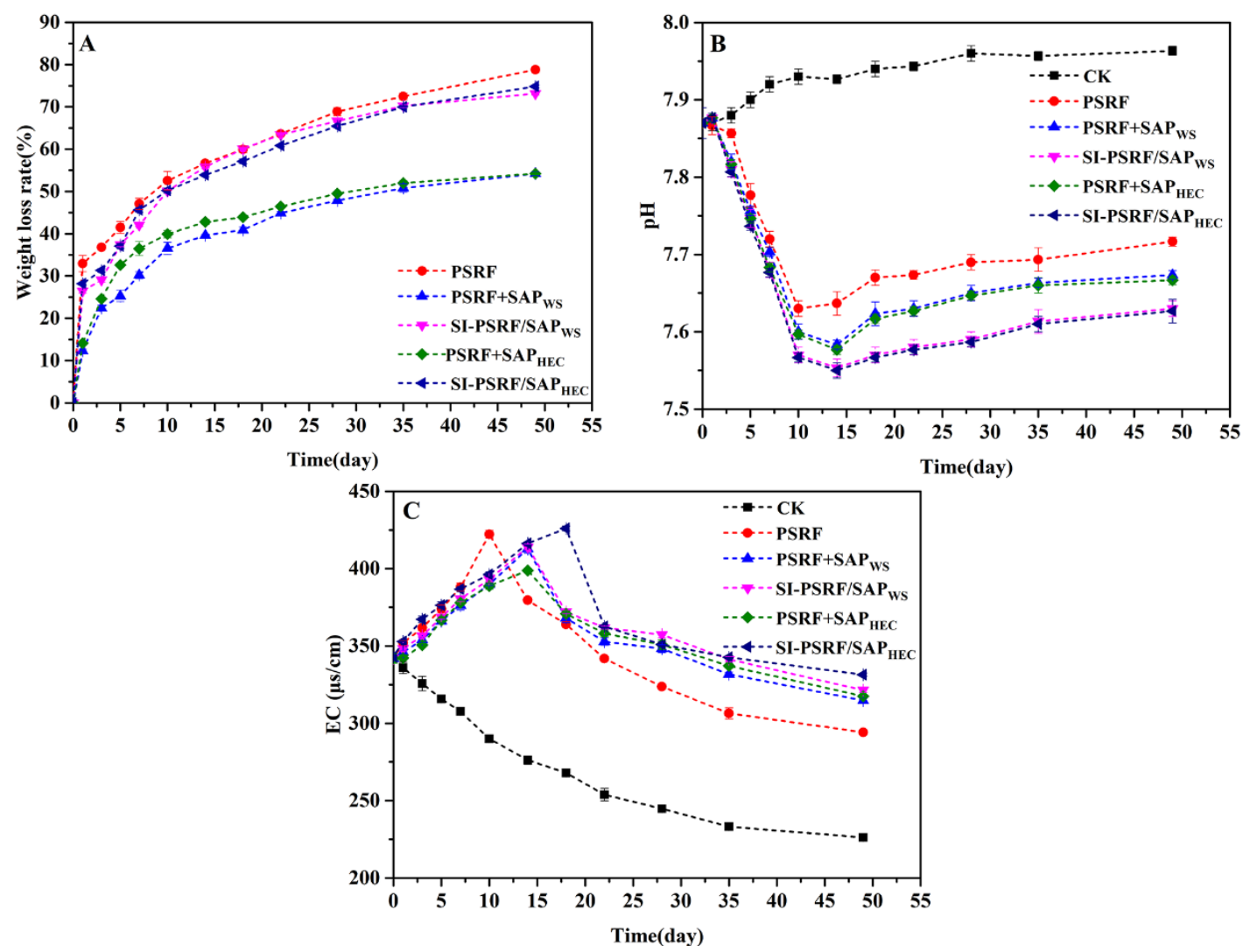

Figure S2. Weight loss rate (A) of PSRF, PSRF+SAP and SI-PSRF/SAP and pH (B),

electric conductivity (C) of soils treated in the soil column leaching experimental.

Dotted lines are only a guide to the eyes. Error bars in the plots represent the average deviation for repeated measurements of three separate samples and the followings are the same. 


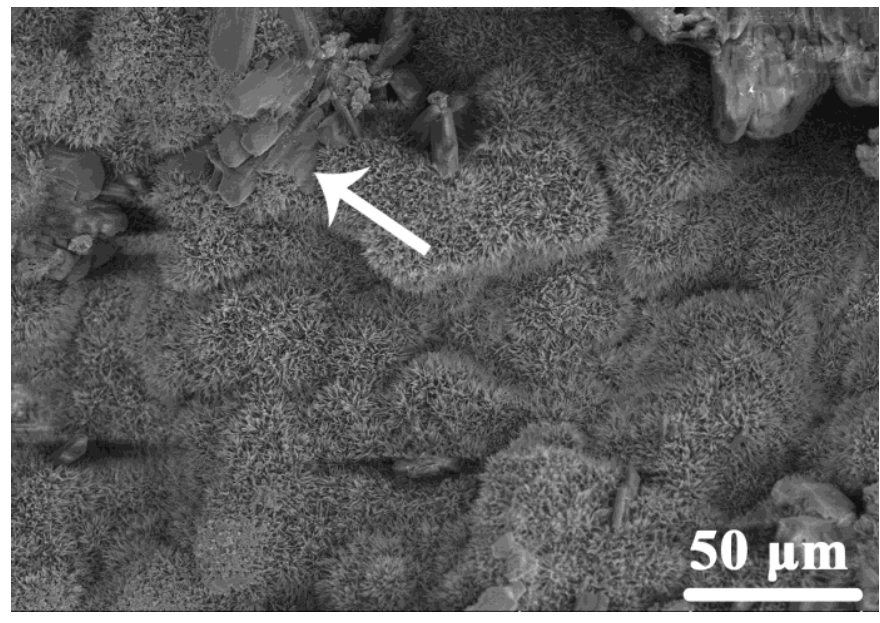

Figure S3. SEM images of PSRF.

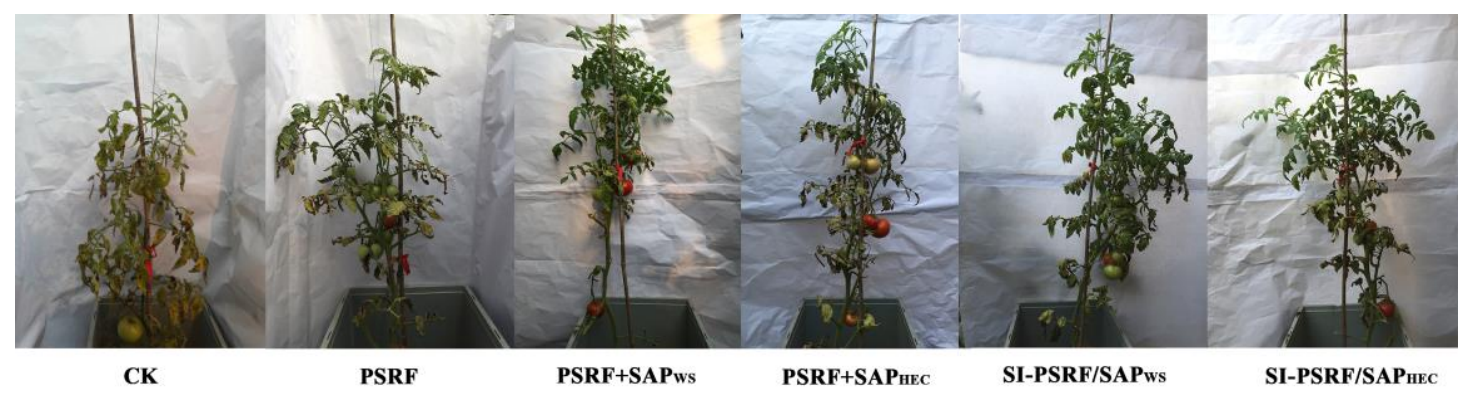

Figure S4. Photographs of representative tomato plants on day 100 of different material treatments. 

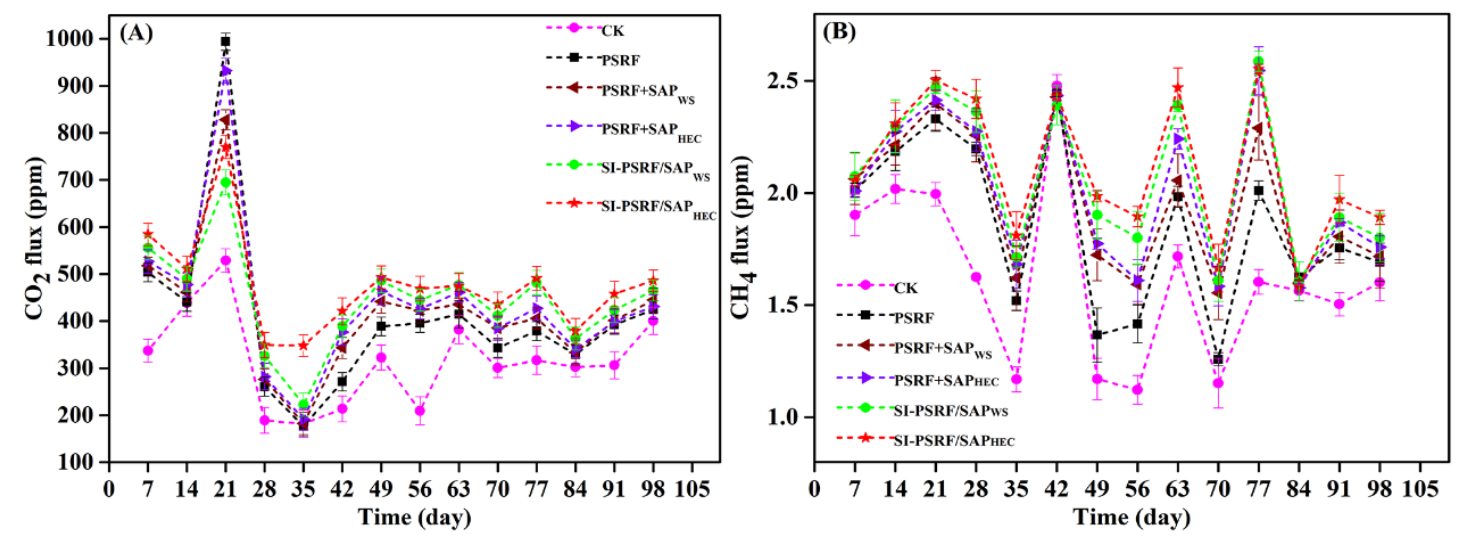

Figure S5. Effects of PSRF, PSRF+SAP and SI-PSRF/SAP on $\mathrm{CO}_{2}$ flux (A) and $\mathrm{CH}_{4}$

flux (B) at different tomato growth periods.

The changes in $\mathrm{CO}_{2}$ emission fluxes were illustrated in Figure S5A, which show the similar trends in different treatments. The $\mathrm{CO}_{2}$ fluxes achieve the highest levels on the 21st day. The reason could be the relatively faster nitrogen release in the early stage, which may strongly increases microbial activity, thereby increasing soil $\mathrm{CO}_{2}$ emissions. Then, the release of fertilizer nitrogen tends to stable, making it difficult to meet the needs of microorganisms, which explains why soil $\mathrm{CO}_{2}$ emissions decrease. SI-PSRF/SAP shows the higher $\mathrm{CO}_{2}$ emission, which could be attributed to the better nitrogen slow-release properties and higher carbon release amounts of SI-PSRF/SAP. Therefore, SI-PSRF/SAP can more effectively improve the mineralization of organic carbon by microorganisms.

The changes in $\mathrm{CH}_{4}$ emission fluxes were illustrated in Figure S5B. The production of $\mathrm{CH}_{4}$ is the last step in anaerobic decomposition. The trends of $\mathrm{CH}_{4}$ emission fluxes are very similar in different treatments. And on day 35,56 and 70 , soil $\mathrm{CH}_{4}$ emissions are at their lowest level. Due to the relatively low soil water content, methanogens have poor activities on $\mathrm{CH}_{4}$ production, while the methanotrophs have poor 
consumptions of $\mathrm{CH}_{4}$. Specifically, SI-PSRF/SAP shows the highest $\mathrm{CH}_{4}$ emission. This further indicates that SI-PSRF/SAP can promote the mineralization of soil organic carbon, thereby improving soil fertility. 